\title{
Comparison in intersectional discrimination
}

\author{
Shreya Atrey ${ }^{* \dagger}$ \\ University of Bristol Law School, University of Bristol, Bristol, UK \\ *Author email: shreya.atrey@bristol.ac.uk
}

(Accepted 6 August 2017)

\begin{abstract}
This article considers the use of comparison in establishing multi-ground claims of intersectional discrimination. Leading examples of test cases from the US and the UK exemplify the challenges in using comparison to establish discrimination against Black women, based on the grounds of both race and sex. These challenges include: the insistence on using a single mirror comparator (viz white men) or the difficulties in choosing multiple comparators from a range of options (viz white women, Asian women, Black men, white men etc); the missing rationale for the selection; and the unwieldiness in actually appreciating the nature of intersectional discrimination based on this exercise. To overcome these, Canadian courts have relaxed the strict requirement of necessarily resorting to comparison for proving discrimination and switched to the flexible approach. However, in practice, flexible approach appears as fastidious as strict comparison in its selection and use of comparators. Thus, neither of the two approaches has been too helpful in supporting intersectional claims. The article argues that instead, a useful way of proving intersectional discrimination is to follow the South African approach of making comparisons contextually: (i) between all relevant comparators, identified in reference to one, some, and all of the grounds or personal characteristics; and (ii) sifting through comparative evidence with the purpose of establishing similar and different patterns of group disadvantage which characterise the nature of intersectional discrimination. This approach brings both principle and purpose to employing comparison and can be especially useful in appreciating intersectional discrimination as based on multiple grounds.
\end{abstract}

Keywords: intersectionality; intersectional discrimination; comparison

\section{Introduction}

The speciality of discrimination law is that the cause (an act, measure, provision, policy, criterion etc) is connected to the effect (discrimination) by 'grounds'. Thus, it is not only necessary to show that something happened and led to an harmful effect, but also that the act was based on or the effects were suffered on the basis of certain personal characteristics or grounds like race, caste, sex, gender, sexual orientation, age, disability etc. ${ }^{1}$ The comparator test helps establish this connection between discriminatory impact and its basis in grounds. It does so in this way: the claimant has to show that a real or hypothetical individual or group, which does not share the claimant's personal characteristic, but is

\footnotetext{
${ }^{\dagger}$ For their invaluable comments on earlier drafts of this article, many thanks are due to Sandra Fredman, Marl Bell, Kate O'Regan, David Oppenheimer, Miles Jackson, Gautam Bhatia, Laurie Jane Anderson, participants of the Resident Fellows Forum at NYU Centre for Human Rights and Global Justice held in April 2016 and members of the Berkeley Comparative Anti-Discrimination Law Virtual Study Group meeting held in January 2015. I am also grateful for the comments of two anonymous peer reviewers which helped shape the final draft of the article.

${ }^{1}$ J Gardner 'On the ground of her sex(uality)' (1998) 18 Oxford Journal of Legal Studies 167; T Khaitan A Theory of Discrimination Law (Oxford: Oxford University Press, 2015) pp 165-171.
}

(c) The Society of Legal Scholars 2018 
otherwise similarly situated, is better off. ${ }^{2}$ Courts can then conclude that discriminatory treatment or impact was based on the personal characteristic of the claimant. For example, in order to claim sex discrimination successfully, a female employee would show that she was treated less favourably by her employer than a man with the same responsibilities and role in an establishment.

But not every case of discrimination yields itself to the comparator test. The ostensible simplicity of this approach can be especially deceptive for intersectional claims based on more than one ground of discrimination. An intersectional claim is one which reflects 'intersectionality'. The term was coined by Kimberlé Williams Crenshaw in 1989 and it stands for the idea that discrimination on the basis of multiple grounds signifies a distinct disadvantage which is both similar to and different from that based on individual grounds. ${ }^{3}$ It can be imagined in terms of the qualities of a Venn diagram such that the portion where the spheres intersect represents some unique features of its own, and also shares some features of the individual spheres. ${ }^{4}$ For example, the position of disabled Black women can be imagined as located at the centre of three intersecting spheres of disadvantage suffered by the groups of disabled persons, Blacks, and women. The point at which all these spheres intersect reflects: (i) the unique disadvantage suffered by disabled Black women, which is not suffered by a group like nondisabled white men in any way since they are located outside of the intersecting spheres; and (ii) the disadvantage they share with disabled persons, Blacks and women, as well as the characteristics of disadvantage of two of these spheres (groups) as disabled women, disabled Blacks, and Black women. In this way, each of the groups located around the intersection signify the distinct nature of intersectional discrimination - as similar and different patterns of group disadvantage - suffered by disabled Black women.

So if a disabled Black woman brings a discrimination claim on the basis of her disability, race, and gender, who would her comparator(s) be $?^{5}$ Would the comparator have to be someone who does not share any of her personal characteristics, ie a non-disabled white man - a universal comparator who

\footnotetext{
${ }^{2}$ See in particular leading judicial and statutory formulations of the comparator tests in the context of the Great Britain in Equality Act 2010, s 23; the US in Teamsters $v$ United States (1977) 431 US 324 [fn 15] (SC); Canada in Hodge v Canada (Minister of Human Resources Development) [2004] 3 SCR 357 [1], [20]ff (SCC) (Hodge) and Withler v Canada [2011] 1 SCR 396 [41]ff (SCC) (Withler); South Africa in MEC for Education, Kwa-Zulu Natal v Pillay 2008 (1) SA 474 (CC) [42]-[44] (Langa CJ), [164]-[165] (O’Regan J).

${ }^{3} \mathrm{KW}$ Crenshaw 'Demarginalizing the intersection of race and sex: a black feminist critique of antidiscrimination doctrine, feminist theory and antiracist politics' (1989) University of Chicago Legal Forum 139 at 149; S Cho, KW Crenshaw and L McCall 'Toward a field of intersectionality studies: theory, applications, and praxis' (2013) 38 Signs 785 at 787.

${ }^{4}$ See for a depiction of the Venn diagram, S Atrey 'Lifting as we climb: recognising intersectional gender violence in law' (2015) 5 Onati Socio-Legal Series 1512 at 1516-1520. See also Figure 1 below. The reference to a Venn diagram here should not be taken to indicate an understanding of intersectionality as intersection of separate spheres of disadvantage (sexism, racism etc) which exist independently and collide only in respect of some intersectional groups (Black women). The fear of this interpretation with the use of Venn diagrams has been noted by D Carbado and M Gulati in Acting White? Rethinking Race in 'Post-Racial' America (New York: Oxford University Press, 2013) p 71. This article adopts a view of intersectionality as representing a form of disadvantage which is fundamentally co-constituted by multiple systems of disadvantage. The Venn diagram aids this understanding by explaining the nature of intersectional disadvantage of some groups like Black women as something similar to, and at the same time, different from disadvantage of other groups like Black men, white women, and white men. It does not undercut the simultaneity, complexity, and co-constitutive nature of intersectional disadvantage, but helps relate it to the framework of discrimination law which is based on grounds and is meant to alleviate the historical and abiding forms of substantial group disadvantage. For a justification of such a basis of discrimination law, see Khaitan, above n 1, N Lacey 'From individual to group' in B Hepple and E Szyszczak (eds) Discrimination: The Limits of the Law (London: Mansell, 1992); M Pieterse 'Finding for the applicant? Individual equality plaintiffs and group-based disadvantage' (2008) 24 South African Journal on Human Rights 397.

${ }^{5} \mathrm{~A}$ preliminary challenge lies in imagining and accepting that such a claim is in fact possible. Sceptics have long doubted whether discrimination other than that based on a single ground exists and if at all it did, how complex could it possibly be? Readers of this article would have to collude with the premise that intersectional discrimination exists in all its complexity as possible. For instance, in Norville v Staten Island University Hospital (1999) 196 F3d 89 (2d Cir), Wendy Norville, a black disabled woman argued that the hospital had discriminated against her by 'refus[ing] to accommodate her disability despite having made job accommodations for two disabled white nurses'. Her claim failed because she could not convince the Court that other similarly situated nurses were treated better. The failure of such complex cases does not obliterate the basis of their
} 
belongs to none of the disadvantaged groups? Or would each ground require a separate comparator obtained by replacing the disadvantaged group with its cognate privileged group, ie for disability a non-disabled Black woman; for race - a disabled white woman; and for gender - a disabled Black man? Or could other comparators which do not share two of the claimant's identities also be relevant, ie disabled white man, non-disabled white woman, non-disabled Black man? Which of the seven possible comparator groups are relevant in proving the claimant's case? ${ }^{6}$ Could we also consider comparators beyond the trite binaries of disabled/non-disabled, white/Black, women/men to see comparator groups more closely based on their nature of disabilities, ethnicities, and genders? What determines these choices and how does it help establish an intersectional claim? This article is dedicated to these inquiries.

Intersectional discrimination has evaded sophisticated discrimination regimes like the US, the UK and Canada. ${ }^{7}$ In the US, after the failure of the seminal test case of intersectional discrimination (DeGraffenreid $v$ General Motors ${ }^{8}$ ), courts have admitted a limited idea of 'sex plus' or 'race plus' discrimination, where each ground has to be proved individually and each such claim is limited to two grounds only. ${ }^{9}$ In the UK, though the Equality Act 2010 (which applies to England and Wales) recognises 'combined discrimination' in section 14, the provision has never been brought into force. Even so, it is limited to direct discrimination based on an exhaustive list of protected characteristics, capping their number in a claim of 'combined discrimination', like the US, to two. The result is in line with the England and Wales Court of Appeal's decision in Bahl v Law Society, ${ }^{10}$ which remains a rare case of a discrimination claim to be argued on two grounds at that level. On the other hand, while the Canadian Supreme Court has generally acknowledged the idea of intersectional discrimination, ${ }^{11}$ it has never adjudicated a claim based on multiple grounds. The Ontario Court of Appeal's decision in Falkiner $v$ Ontario $^{12}$ is often seen as a leading example which comes close to, but is ultimately not on all fours with, intersectionality. ${ }^{13}$ In contrast, the South African Constitution under Section 9(3) recognises that discrimination could be based on 'one or more grounds' and the Constitutional Court has received such multi-ground claims favourably. ${ }^{14}$ But the concept of intersectional discrimination is far from mainstream in any of these discrimination regimes. ${ }^{15}$ The fact that the reservoirs of

existence and only goes to show that such discrimination can exist, whether or not we choose to address it qua discrimination law.

${ }^{6}$ Mathematically, the number of possible comparators - groups which share none of the characteristics and those which share one or some of the characteristics - for a claim involving ' $N$ ' number of grounds can be calculated based on the formula: $C_{N}:=\sum_{k=1}^{N}\left(\begin{array}{c}N \\ k\end{array}\right)$. Here, $\left(\begin{array}{c}M \\ l\end{array}\right):=\frac{M !}{(M-l) ! l !}$ is a binomial coefficient, $l !:=l(l-1)(l-2) \ldots 2$ is a factorial, and the sum goes over all $\mathrm{k}$ from 1 to $\mathrm{N}$. For instance, for a claim of three characteristics or grounds, based on the formula, $C_{3}=$ comparisons can be made by a court. The question remains how does one actually choose from and use the array of possible comparators in intersectional claims.

${ }^{7}$ S Fredman Discrimination Law (London: Oxford University Press, 2nd edn, 2011) pp 139-145.

${ }^{8} 413$ F Supp 142 (ED Mo 1976) (DeGraffenreid).

${ }^{9}$ Jefferies v Harris County Community Action Association (1980) 615 F2d 1025 at 1033 (5th Cir); Vasquez v County of LA (2003) 349 F3d 634 (9th Cir); Rogers v American Airlines, Inc (1981) 527 FSupp 229 (SDNY); Coleman v B-G Maintainence Management, Inc (1997) 108 F3d 1199 (10th Cir).

${ }^{10}$ [2004] EWCA Civ 1070 (England and Wales Court of Appeal) (Bahl).

${ }^{11}$ Mossop v Canada (Attorney General) [1993] 1 SCR 554 at 645 (SCC) L’Heureux-Dubé J, dissenting) (Mossop).

${ }^{12}$ [2002] OJ No 1771 (Court of Appeal for Ontario) (Falkiner).

${ }^{13}$ See D Gilbert and D Majury 'Critical comparisons: the Supreme Court of Canada dooms section 15' (2006) 24 Windsor Year Book of Access to Justice 111; D Majury 'The Charter, equality rights, and women: equivocation and celebration' (2002) 40 Osgoode Hall Law Journal 297.

${ }^{14}$ Bhe v Magistrate, Khayelitsha 2005 (1) SA 580 (CC); Hassam v Jacobs (NO) [2009] ZACC 19 (CC) (Hassam).

${ }^{15}$ This has not discouraged seminal contributions on the subject which include: G Moon 'Multiple discrimination: justice for the whole person' (2009) 2 Journal of the European Roma Rights Centre 5; JC Nash 'Re-thinking intersectionality' (2008) 89 Feminist Review 1; J Conaghan 'Intersectionality and UK equality initiatives' (2007) 23 South African Journal on Human Rights 317; I Solanke 'Putting race and gender together: a new approach to intersectionality' (2009) 72 Modern Law Review 723; S Hannett 'Equality at the intersections: the legislative and judicial failure to tackle multiple discrimination' (2003) 23 
discrimination jurisprudence remain high and dry of intersectional claims has spurred a critical examination of the body of discrimination law and its central concepts like grounds in assisting complex cases of discrimination. ${ }^{16}$ The article contributes to this line of inquiry by analysing another central aspect of discrimination law - the heuristic of comparison - to examine what about this chief tool makes it highly resistant to intersectionality and thus makes intersectional claims highly unlikely to succeed.

The article proceeds as follows. In Part 2, I take the examples of DeGraffenreid and Bahl to show that the approach of 'strict' comparison, ie the requirement of using a single mirror comparator to establish a multi-ground claim, is untenable because: (i) the selection of comparators based on this approach is too unprincipled and complicated; and (ii) their use ultimately fails to explicate the intersectional nature of disadvantage based on multiple grounds. In Part 3, I consider the case of Falkiner to see if the 'flexible' approach to comparison alleviates the enduring concerns. While the flexible approach eliminates the necessity of a single mirror comparator, its own use of multiple comparators is as fastidious as in strict comparison and in fact left unsubstantiated. Part 4 then proceeds to offer an alternative to the strict and flexible approaches to comparators. The South African example of Hassam presents a healthy halfway house in using comparison, as a helpful heuristic rather than as a requirement for establishing intersectional discrimination. Hassam's 'contextual' approach of closely analysing the similarities and differences between all relevant comparator groups exemplifies how recourse to comparison can be made in a principled and purposeful way to establish intersectional claims.

It is useful to note that the references from the US, the UK, Canada and South Africa are not meant for the purpose of comparing their respective doctrinal positions; but to shine a spotlight on the key approaches to comparison in multi-ground claims which served as test cases of intersectional discrimination in these jurisdictions. Because of the lack of an established or successful record of intersectional claims, these early attempts are telling in their quest for making comparison respond to intersectionality and in turn the quest for making intersectional claims successful in discrimination law. The point this limited but incisive doctrinal survey makes is then a conceptual one: that the judicial use of comparison often does not accord with the requirements of multi-ground intersectional claims. In order that comparison may still be useful, it needs to be reimagined within the existing discourse of discrimination law in reference to the demands of intersectionality. Thus, in proposing contextual comparisons, the article contributes to the goal of overcoming what Crenshaw called 'dominant ways of thinking about discrimination'. ${ }^{17}$ The article furthers the project of transforming the traditional boundaries of discrimination law based on a single ground, to accommodate multi-ground claims of intersectional discrimination, via a recalibrated vision of comparison.

\section{Strict comparison}

Some form of comparison or relative disadvantage is necessary in proving 'discrimination' under sections 703-704 of the Civil Rights Act 1964 of the US; 'less favourable treatment' or 'particular disadvantage' under sections 13, 14 and 19 of the Equality Act 2010; 'discrimination' under section 15(1) of the Canadian Charter; or 'differentiation' and 'unfair discrimination' under section 9(3) of the South African Constitution. However, the form and content of the comparator requirement differs substantially between jurisdictions.

Strict comparison can be earmarked as one where it is necessary to use a real or hypothetical comparator in order to show relative disadvantage based on grounds for proving wrongful discrimination.

Oxford Journal of Legal Studies 65; D Kropp "Categorical" failure: Canada's equality jurisprudence - changing notions of identity and the legal subject' (1997) 23 Queen's Law Journal 201.

${ }^{16}$ Excellent analyses on the nature of grounds and their categorical application appear in: D Gilbert 'Time to regroup: rethinking section 15 of the Charter' (2003) 48 McGill Law Journal 627; DG Réaume 'Of pigeon holes and principles: a reconsideration of discrimination law' (2002) 40 Osgoode Hall Law Journal 113; D Pothier 'Connecting grounds of discrimination to real people's real experiences' (2001) 13 Canadian Journal of Women and Law 3925; N Iyer 'Categorical denials: equality rights and the shaping of social identity' (1993) 19 Queen's Law Journal 179.

${ }^{17}$ Crenshaw, above n 3 , at 150 . 
The appropriate comparator is one 'with whom the claimant shares the characteristics relevant to qualification for the benefit or burden in question apart from the personal characteristic that is said to be the ground of the wrongful discrimination'. ${ }^{18}$ The exercise of finding this single 'mirror' comparator is strict, ie it is necessary for establishing discrimination.

This version of the comparator test has been popular in the US and the UK, and in Canada until recently. In the US, though not statutorily required, strict comparison is essential to proving discrimination. ${ }^{19}$ The UK test is similar, in that the comparison has to be with someone who closely resembles the claimant but for the personal characteristic being pleaded as the ground of discrimination. ${ }^{20}$ The Canadian Supreme Court too, before switching to the flexible approach described in the next section, had considered strict comparison central to discrimination cases. ${ }^{21}$

Strict comparison - primarily devised for single-ground claims - does not neatly transpose onto multi-ground intersectional claims. As the cases below show, the demand of finding mirror comparators has devolved into two options in intersectional claims - first, finding a single mirror comparator which did not share any of the personal characteristics of the claimant but was similarly situated otherwise; secondly, finding a mirror comparator for each ground individually. ${ }^{22}$ Both the options, however, seem to have failed in supporting intersectional claims.

The Court of Appeal struggled with both these choices in Bahl. The claimant in the case, Dr Kamlesh Bahl, was a Black Asian woman who had served as the Vice President of the Law Society. She alleged that she had been discriminated against on the basis of race and sex, by members of the Law Society in the determination of staff complaints against her. Gibson LJ laid down the following approach for testing her claim: 'identify what evidence goes to support a finding of race discrimination and what evidence goes to support a finding of sex discrimination' such that 'the evidence for each form of discrimination was [not] the same'. ${ }^{23}$ He insisted that for a claim of race and sex discrimination to succeed, the claimant should be able to prove both race and sex discrimination separately

\footnotetext{
${ }^{18}$ Hodge, above n 2, paras [1], [23] (emphasis in original).

${ }^{19}$ US Civil Rights Act 1964, Title VII, ss 703-704. See Ash v Tyson Foods, Inc (2006) 546 US 454 (SC); Miller-El v Dretke (2005) 545 US 231 (SC); Knight v Baptist Hospital of Miami, Inc (2003) 330 F3d 1313 (11th Cir); Gossett v Okla ex rel Bd of Regents for Langston University (2001) 245 F3d 1172 (10th Cir); Paluck v Gooding Rubber Co (2000) 221 F3d 1003 (7th Cir); Holifield v Reno (1997) 115 F3d 1555 (11th Cir); O'Connor v Consol Coin Caterers Corp (1996) 517 US 308; Patterson v McLean Credit Union (1989) 491 US 164 (SC); McDonnell Douglas Corp v Green (1973) 411 US 792 (SC). See also CA Sullivan 'The phoenix from the ash: proving discrimination by comparators' (2009) 60 Alabama Law Review 191 at $204-$ 206; EF Lidge III 'The courts' misuse of the similarly situated concept in employment discrimination law' (2002) 67 Missouri Law Review 831 at 839.

${ }^{20} R$ v Birmingham County Council ex p Equal Opportunities Commission [1989] AC 1155, HL; Great Britain, Equality Act 2010, ss 13, 14, 19, 23. See also the Sex Discrimination Act 1975, ss 1(1), 5(3) and Lord Nicholls' observation in Shamoon $v$ Chief Constable of the Royal Ulster Constabulary [2003] UKHL 11 at [4] and Dillon LJ in Bain v Bowles [1991] IRLR 356 at 357. Cf Lord Nicholls' qualification in Shamoon: 'employment tribunals may sometimes be able to avoid arid and confusing disputes about the identification of the appropriate comparator by concentrating primarily on why the claimant was treated as she was... The most convenient and appropriate way to tackle the issues arising on any discrimination application must always depend upon the nature of the issues and all the circumstances of the case': ibid, at [11]-[12].

${ }^{21}$ Andrews $v$ Law Society of British Columbia [1989] 1 SCR 143 at 164 (McIntyre J) (SCC); Hodge, above n 2, paras [1], [20]ff.

${ }^{22}$ Although the 'sex plus' and 'race plus' approach in the US has meant that the second option in practice involves, for example, claimants such as women with young children to show difference between their position in comparison to men without the 'plus' characteristic of being parents of young children, ie using a single comparator even in 'plus' cases by taking into account the 'main' ground of discrimination only. The jurisprudence since DeGraffenreid, thus, barely speaks to intersectional discrimination: Derungs v Wal-Mart Stores, Inc (2004) 374 F3d 428 (6th Cir); Martinez v NBC Inc (1999) 49 FSupp2d 305 (SDNY); Coleman v B-G Maintenance Management of Colorado, Inc (1997) 108 F3d 1199 (10th Cir); Fuller v GTE Corporation/Contel Cellular, Inc (1996) 926 FSupp 653 (MD Tenn); Fisher v Vassar College (1995) 70 F3d 1420 (2nd Cir). Cf McGrenaghan v St Denis School (1997) 979 FSupp 323 (ED Pa), where the claimant, a mother of a disabled child, successfully proved sex plus discrimination when she compared herself to the woman without disabled children (who had replaced her). It is, though, useful to note that the claimant also had direct evidence of discriminatory animus on the part of the employer.

${ }^{23} \mathrm{Bahl}$, above n 10 , at [137].
} 
such that discrimination was based on 'either race or sex'. ${ }^{24}$ Having announced that the claimant must show discrimination separately based on each ground, somewhat surprisingly, Gibson LJ then asked the claimant to show how her disadvantage as a Black woman was different from a white male. ${ }^{25}$ Since there was no other position comparable to that of the Vice President, with the same responsibilities and profile, he advised using a hypothetical comparator instead: 'In a unique case such as that of Dr Bahl it is essential to ensure that the hypothetical comparator is a Vice-President who is on the receiving end of serious allegations of bullying but who is a white male ${ }^{26}$ After examining the copious evidence presented before the Court, he dismissed Dr Bahl's complaint for failing to reveal discriminatory reasons for her treatment as either race or sex based. ${ }^{27}$ The Court's choice of treating the two grounds of race and sex separately but using a single comparator to prove both seems to have beleaguered Dr Bahl's claim in four compounded ways.

First, the demand for proving race and sex discrimination separately and the insistence on using a single comparator of a white male to prove both, are fundamentally incompatible. On the face of it, strict comparison on the basis of race would have yielded the comparator of a white female, ie someone who does not share the personal characteristic of being Black but is similarly situated otherwise, including in terms of gender, like a Black woman. Similarly, strict comparison for sex would have yielded Black male as the appropriate comparator. If the Court of Appeal meant to discard these two comparators based on the individual grounds of race and sex in favour of a comparator which did not share any of the claimant's personal characteristics, its initial demand for proving race and sex discrimination separately makes little sense. In going along with a single comparator of a white male, the Court seems to suggest that strict comparison in cases of multi-ground intersectional discrimination has to be one which relates to a mirror comparator who does not share any of the claimant's personal characteristics.

But secondly, the choice of a single comparator of a white male fails in fundamentally appreciating the nature of an intersectional claim. This is because it only speaks to the unique nature of the disadvantage suffered as a Black woman, but disregards the possibility of recognising any shared patterns of disadvantage with women and Blacks generally, and using evidence relating to these groups to establish intersectional discrimination as a matter of similarity and difference in patterns of group disadvantage transpiring simultaneously on multiple grounds. The understanding that intersectional claims can be appreciated in reference to what the claimant shares with other groups who are also disadvantaged based on just one or some of the grounds in a multi-ground claim thus falls by the wayside. ${ }^{28}$ In other words, such a comparison belies the complexity of intersectionality understood as a Venn diagram showing similar and different patterns of group disadvantage at the same time. Instead, it views such discrimination through the lens of single-ground framework which is appreciated not in terms of complex and concrete relationships of disadvantage between intersecting groups but always in contrast with or in opposition to the most privileged cognate group. ${ }^{29}$

Thirdly, the choice reveals the underlying judicial assumption that grounds like race and sex are defined by the binaries of Black-white and female-male, comparing disadvantaged groups to a single paradigmatic dominant group. ${ }^{30}$ As Fredman remarks, the assumption here is that the abstract

\footnotetext{
${ }^{24} \mathrm{Ibid}$, at [115]-[137]. This route to examining a multi-ground claim may have resulted from the atomised nature of the UK discrimination law at the time when sex was a protected ground under Sex Discrimination Act 1975 and racial discrimination was prohibited separately under the Race Relations Act 1976.

${ }^{25}$ Ibid, at [103].

${ }^{26}$ Ibid.

${ }^{27}$ Ibid, at [101], [126], [134], [147].

${ }^{28}$ A McColgan 'Reconfiguring discrimination law' [2007] Public Law 74 at 81.

${ }^{29}$ See S McIntyre 'Answering the siren call of abstract formalism with the subjects and verbs of domination' in M Denike, $\mathrm{F}$ Faraday and MK Stephenson (eds) Making Equality Rights Real: Securing Substantive Equality Under the Charter (Toronto: Irwin Law, 2009).

${ }^{30}$ Majury, above n 13, at 306; R Jhappan 'The equality pit or the rehabilitation of justice' (1998) 10 Canadian Journal of Women and Law 60 at 79.
} 
comparator be 'clothed with the attributes of the dominant gender, culture, religion, ethnicity, or sexuality'. ${ }^{31}$ By formulating comparators this way, in a claim of race and sex discrimination, courts also assume other characteristics of privilege in being a (middle-class non-disabled heterosexual) white male. If it is expected for the comparator to be privileged in most ways but for the claimant's personal characteristic, the perfect comparator for an intersectional claim will then inevitably be a middle-class heterosexual non-disabled white male, ie someone whose personal characteristics are defined only by privilege. Such a comparator would fit any intersectional case, whether of a Muslim gay man or a disabled Sikh woman, because the hypothetical comparator will never share any of the disadvantaging characteristics with the intersectional claimant. Insistence on a comparator, who is privileged as against all disadvantaging identities, marks an unrepresentative norm which creates 'powerful conformist pressures' for claimants in discrimination law. ${ }^{32}$ Claimants with multiple disadvantaging identities may find it difficult to show difference in treatment or adverse impact as compared to this gold standard of a dominant comparator. Dr Bahl's own claim resonated little with this hypothetical comparator because it was too removed from her actual position to reveal anything salient about how she was treated. The choice of a single dominant comparator group thus appears burdensome and perhaps inaccurate in pinning down the basis of intersectional discrimination in multiple grounds, and in similar and different patterns of group disadvantage.

Finally, the Court's ultimate examination of testimonial evidence to discern the 'the reason why ${ }^{33}$ the claimant was treated as she was, had nothing to do with whether a white male would have been treated in the same way as Dr Bahl. Since at no point does the Court actually refer to how its preferred comparator would have been treated in Dr Bahl's situation, the invocation of strict comparison appears without purpose.

These difficulties show that strict comparison with a single mirror comparator, whether real or hypothetical, may be too far removed from the close fit it promises in linking the precise nature of disadvantage to multiple grounds of discrimination. In fact, as the judicial meandering in one of the first US test cases (DeGraffenreid) shows, the normative and operational difficulties outlined above in applying strict comparison cannot be avoided even when the Court applies multiple comparators based on each ground individually instead of a single mirror comparator.

In DeGraffenreid, the District Court of Missouri rejected that the 'last hired-first fired' policy of General Motors discriminated against Black women on grounds of race and sex. In a rather terse judgement, the Court used two sets of comparisons to defeat the challenge. First, the Court used the statistics of favourable hiring of 'female employees' to dismiss the claim of sex discrimination. ${ }^{34}$ It compared Black women to those who shared their personal characteristic as women, ie white women, and yet were better off. Once again, the invocation of strict comparison in this context is suspect. The Court had found that the lawsuit must be examined to see if it states a cause of action for race discrimination, sex discrimination, or alternatively either, but not a combination of both'. ${ }^{35}$ If it meant to treat Black women's claim as two independent claims - one each on the ground of race and sex - its comparators too would have simply resembled those in single ground claims of race and sex. A strict comparison for sex discrimination would have pointed towards a mirror comparator which did not share the claimant's sex, ie Black men or white men. ${ }^{36}$ Instead the Court compared claimants not with people who did not share their personal characteristic, but those who did and were still not disadvantaged. Such a comparison obviously defeated the claim of sex discrimination and also

\footnotetext{
${ }^{31}$ Fredman, above n 7, p 11.

${ }^{32}$ Ibid, pp 11, 168.

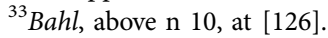

${ }^{34}$ DeGraffenreid, above $\mathrm{n} 8$, at 144 .

${ }^{35} \mathrm{Ibid}$, at 143 .

${ }^{36}$ This being a recognised route for proving dual ground ('sex plus' or 'race plus') cases in the US, ie to find strict or mirror comparators based on each personal characteristic separately, and normally just for the main ground (rather than the 'plus' characteristic) as in cases of single-ground discrimination. See nn 19-22ff.
} 
delimited the possibility of using white women's experiences for analysing comparative disadvantage based on race. The latter is significant for appreciating intersectional discrimination.

The evidence of favourable treatment of white women could have been used to point towards the uniqueness of Black women's disadvantage based on race. ${ }^{37}$ Instead of appreciating this, the Court dismissed the experience of Black women as being a part of sex discrimination at all or as showing racial discrimination between Black women and white women. Both the unusual invocation of strict comparison for the ground of sex, as well as the inability to use the comparison with white women as indicative of the race based disadvantage of Black women, thus depleted the Court's ability to not only look for intersectional discrimination but also to independently establish race or sex discrimination. In effect, neither did the Court identify the right mirror comparator according to the tenets of strict comparison, nor did it use its preferred comparator to help appreciate intersecting forms of disadvantage.

Secondly, in relation to race discrimination (and in contrast with its position on sex discrimination), the Court equated the claim of Black women to that of Black men and found that race discrimination was not to be construed differently for the two groups. In doing so, the Court consolidated the present claim with a similar race discrimination claim sub judice in the Court. ${ }^{38}$ Its refusal to decide the matter in this instance was based on the suggestion that the experience of race discrimination was the same for Black men and women, thereby denying the possibility of using Black men's experiences in appreciating the uniqueness of race discrimination suffered by Black women when it intersects with gender. Thus, the comparator group of Black men: (i) conflated the similarities in the experiences of race discrimination such that the Black women's experiences were subsumed within race discrimination alone; and at the same time; (ii) deflated the difference in the experiences of sex discrimination, by disconnecting Black women's experiences from white women completely. In this way, Black women in DeGraffenreid fell through the cracks of both race and sex discrimination. ${ }^{39}$

But the Court could have compared the claimants to white women and Black men and inferred from their relative advantage, Black women's disadvantage associated with race and sex discrimination respectively, instead of denying sex and race discrimination at all. In failing to appreciate intra-group differences and inter-group similarities across different grounds, the Court missed intersectional discrimination with its constricted use of strict comparison.

In sum, two principal problems emerge in employing strict comparison in multi-ground intersectional claims like Bahl and DeGraffenreid. First, there is a lack of a background principle mediating the choice of comparators which exposes a normative gap in the judicial thinking responding to intersectional claims via strict comparison. As discussed above, neither the DeGraffenreid approach of choosing separate comparator groups nor the Bahl approach of a single dominant comparator group seem to be conceptually justifiable. If comparison must necessarily be invoked in establishing intersectional claims, it is only appropriate to ask on what basis are the comparators chosen.

Secondly, the choice of comparators reflects an understanding of single-ground or multiple discrimination rather than intersectional discrimination. Multiple discrimination reflects an understanding of discrimination based on multiple grounds individually, such that discrimination needs to be

\footnotetext{
${ }^{37}$ This is exactly what the female claimant argued in Philipsen $v$ University of Michigan Board of Regents (2007) No 2:2006CV11977 (ED Mich) ("Plaintiff argues that in "sex-plus" discrimination claims, such as those she is asserting against Defendant, she need not show disparate treatment of a male comparator. Instead, she argues that she can satisfy her burden by showing that women without young children were treated differently than women with young children'). The Court though disagreed, being 'more persuaded by those that require the comparator to be outside of the protected class'.

${ }^{38}$ DeGraffenreid, above n 8, at 145 .

${ }^{39}$ This approach has now been fortified to defeat Black women's claims in a way such that evidence relating specifically to Black women is seen as showing a basis for neither race nor sex discrimination. For example, in Anthony, the Court observed that 'the epithet "black bitch" cannot be designated exclusively as either racist or sexist': Anthony v County of Sacramento (1995) 898 F Supp 1435, 1445 (ED Cal). Similarly in Lam, the Court observed that the lack of evidence of discrimination against Asian men or white women would not confirm specific forms of discrimination against Asian women per se: Lam v University of Hawaii (1994) 40 F3d 1551, 1562 (9th Cir).
} 
proved based on each ground separately. ${ }^{40}$ This thinking is rooted in single-ground discrimination, in that discrimination is seen as ultimately occurring on a single ground either alone or, in case of multiple grounds, as occurring discreetly and successively based on each. DeGraffenreid mirrors this approach in treating grounds as abstract and isolated such that they can be examined separately, rather than as intersecting to produce similar and different patterns of group disadvantage. The harm, as Gilbert and Majury point out, is that: 'The claimants are not treated as whole people and the interactive nature of the sites of oppression is rendered invisible, even negated'. ${ }^{41}$ This harm of treating claimant's identities as 'severable and unrelated'42 instead of a whole, ultimately exacerbates the difficulty in appreciating the salience of an intersectional claim, ie similar and different patterns of disadvantage created by the intersection of multiple identities. This salience can only be appreciated when the claimant's group identities are considered together, ie as a whole (like a Venn diagram), rather than by considering each identity or group (sphere) individually in isolation. The judicial failure thus lies in neglecting to fundamentally understand intersectional discrimination and in purposefully moulding comparison to respond to it.

\section{Flexible comparison}

Strict comparison continues to attract severe criticism not just for its incompatibility with intersectional claims, but also in failing to support traditional single-ground claims. ${ }^{43}$ In response, the Canadian Supreme Court proposed the flexible approach, which makes it unnecessary to pinpoint a particular group that precisely corresponds to the claimant group except for the personal characteristic or characteristics alleged to ground the discrimination'. ${ }^{44}$ Instead, it reaffirms the 'general usefulness' of comparison in establishing discrimination, ${ }^{45}$ and the possibility of employing single, multiple or no comparator(s). ${ }^{46}$ While the Supreme Court has never adjudicated a multi-ground discrimination claim, this proposal was based on the estimation that 'flexibility [could] accommodate claims based on intersecting grounds of discrimination'. ${ }^{47}$ It is then useful to evaluate flexible comparison in light of its motivation for supporting intersectional claims.

Does the flexible approach alleviate the challenges of strict comparison? What is its basis for abandoning comparison or allowing more than one comparator and for choosing between multiple comparators? The Ontario Court of Appeal's extended discussion in Falkiner illustrates a rare instance of using the flexible approach for establishing intersectionality and provides ample fodder for these inquiries.

In Falkiner, the claimants challenged the 'spouse in the house rule' under Ontario's social assistance legislation which deemed them to be spouses as soon as they started cohabiting with their partners and thus excluded them from social assistance. The claimants were single women, with dependent children and in need of social assistance. Their case was that the rule caught casual try-on relationships which were not actually 'spousal'. In being over-inclusive, it perpetuated the pre-existing disadvantage of single mothers on social assistance by excluding them from the beneficial legislation. This challenge was framed by the claimants as based on either sex or a combination of sex, marital status, and receipt of social assistance. The Court found that the impugned rule violated section 15(1) of the Canadian

\footnotetext{
${ }^{40}$ See also Bahl, above n 10, at [115]-[137].

${ }^{41}$ Gilbert and Majury, above n 13, at 134.

${ }^{42}$ Ibid.

${ }^{43}$ See S Reibetanz Moreau 'Equality rights and the relevance of comparator groups' (2006) 5 Journal of Law and Equality 81; Réaume, above n 16; Pothier, above n 16; Gilbert, above n 16; Gilbert and Majury, above n 13.

${ }^{44}$ Withler, above n 2, at para [41]ff. Some US courts have followed a somewhat similar relaxed approach to comparison in 'sex plus' cases by bypassing the requirement to show differentiation as against men: Back v Hastings On Hudson Union Free School District (2004) 365 F3d 107 (2nd Cir); Trezza v Hartford, Inc (1998) No 98 Civ 2205, (SDNY). See n 37ff.

${ }^{45}$ Quebec v A [2013] 1 SCR 61 [169] (SCC).

${ }^{46} \mathrm{~J}$ Koshan and J Hamilton 'Meaningless mantra: substantive equality after Withler' (2011) 16 Review of Constitutional Studies 31 at 53 .

${ }^{47}$ Withler, above n 2, at paras [58], [63].
} 
Charter on 'the combined grounds of sex, marital status and receipt of social assistance ${ }^{\text {,48 }}$ and the discrimination was unjustifiable under section 1. It reached this decision based on an elaborate application of the 'flexible comparative approach [which] reflect[ed] the complexity and context of the respondents' claim... ${ }^{49}$ It did so by allowing a 'set of comparisons, each one bringing into focus a separate form of differential treatment'. ${ }^{50}$ The set of comparisons were based on each ground individually, and are set out in Table 1 below: ${ }^{51}$

Table 1. Comparator groups in Falkiner

\begin{tabular}{lll}
\hline Ground & Claimant's Choice & Court's Substitution \\
\hline Sex & Men on social assistance & Single men on social assistance \\
\hline Marital Status & $\begin{array}{l}\text { Social assistance recipients } \\
\text { who are not single mothers }\end{array}$ & Married people on social assistance \\
\hline Social Assistance & Persons not on social assistance & Single persons not on social assistance \\
\hline
\end{tabular}

Two questions must be asked here: first, what governed the flexibility in choosing the appropriate comparators? Secondly, does the approach resonate with the nature of intersectional discrimination? If the reasoning in Falkiner offers clear guidance in these two respects, the flexible approach can indeed be confirmed as reflecting 'the complexity and context' of the intersectional claim. But as the forthcoming analysis shows, Falkiner neither reveals a principled approach in using comparators flexibly nor does it help appreciate intersectional discrimination in the way multiple comparisons are chosen based on each ground individually.

The Court's approach to fine-tuning the comparators offered by the claimants remains unsubstantiated in its reasoning. In the first instance, to support a finding on the ground of social assistance the Court substituted the claimant's choice of 'persons not on social assistance' with 'single persons not on social assistance'. Its explanation was that the comparison offered by the claimant 'does not, on its own tell us anything meaningful beyond the fact that people on social assistance are treated financially differently than people not on social assistance'. ${ }^{52}$ On the other hand, the substitute comparator was preferable because:

Framing the comparison in this way [as single persons not on social assistance] shows that the respondents have been treated unequally. They have suffered adverse state-imposed financial consequences because they began living in try-on relationships. By contrast, single people who are not on social assistance are free to have these relationships without attracting any kind of state-imposed financial consequences. ${ }^{53}$

What, other than the Court's own belief in its comparator group, shows unequal treatment better than the contender offered by the claimant or other possible comparator groups? There is no more on record which helps us to understand the Court's choice. It is worth asking why the same result would not have followed from a comparator like 'single women not on social assistance', 'single mothers not on social assistance', or simply with the claimant's choice of 'persons not on social assistance'. Each of these possible alternatives could show that any single person not on social assistance had the agency and resources to pursue try-on relationships without suffering the disadvantage suffered by the claimants specifically. It appears that the Court's refinement is motivated by constructing as narrow a

\footnotetext{
${ }^{48}$ Falkiner, above $\mathrm{n} 12$, at para [105].

${ }^{49}$ Ibid, at para [81].

${ }^{50}$ Ibid, at para [71] (emphasis supplied).

${ }^{51}$ It is useful to note that unlike other cases, it was not the government which offered revised comparators, but the Court which took upon itself to find the most suitable comparators.

${ }^{52}$ Gilbert and Majury, above n 13, at 135.

${ }^{53}$ Falkiner, above n 12, at para [73].
} 
comparator as possible in strict terms based on a single ground at a time, such that social assistance was the only material difference between the claimants and the comparator group. But such a premise remains unarticulated and leaves hanging the question why the narrow comparator did not entail single mothers specifically. Even if comparison with single mothers not on social assistance revealed similar patterns of disadvantage rather than a position of advantage, it would have been relevant in establishing the connection with sex discrimination, ie patterns of disadvantage based on sex which interact with other grounds like dependence on social assistance, and child-care or marital status to produce both similar and different patterns of disadvantage for an intersectional claimant. But once again, the exercise of comparing advantage against disadvantage of cognate groups like in DeGraffenreid, overshadows comparison across grounds (and groups) to find similarities and differences which are the crux of an intersectional claim. The result resembles single-ground focus of strict comparison in effect.

In finding for sex as the basis of differentiation, the Court shifts the comparator group from 'men on social assistance' to 'single men on social assistance' but finally decides not in reference to either of these but on the basis of available statistics directly relating to women and single mothers. According to Laskin JA, 'the statistics unequivocally demonstrate that both women and single mothers are disproportionately adversely affected'. ${ }^{54}$ As he explained:

although women accounted for only 54 per cent of those receiving social assistance and only 60 per cent of single persons receiving benefits, they accounted for nearly 90 per cent of those whose benefits were terminated by the definition of spouse. The corresponding figures for single mothers also show the definition's disproportionate impact on that group. ${ }^{55}$

These statistics led him to make a partial conclusion to the point that: 'respondents [were] subjected to differential treatment on the basis of sex'. ${ }^{56}$ If according to the statistics, single mothers on social assistance were in fact demonstrably worse-off, this finding could go on to support marital status as well as social assistance as markers (grounds) of differential impact. The statistical evidence in relation to the claimants themselves was perhaps all that was needed for the Court to make a determination in this case rather than going down the circuitous route of comparators which consumed most of the Court's analysis. At least, under a flexible approach true to its terms which allows not necessarily relying on comparators, the Court could have foregone hustling with comparators for establishing sex discrimination or even discrimination on the combined basis of sex, marital status and receipt of social assistance. But since the evidence on record clearly showed relative disadvantage, the search for a definitive comparator group for each ground seems as redundant as disingenuous.

The fragmented use of comparative evidence to support separate grounds individually rather than seeing discrimination as accruing on the basis of intersecting grounds also undermines the concept of intersectional discrimination. To remind, framing comparators for each ground individually and using statistics to establish a single ground at a time, promotes an understanding of single-ground or multiple discrimination rather than intersectional discrimination, ${ }^{57}$ the underlying assumption being that a multiground claim can be neatly broken down based on each personal characteristic to prove discrimination as a matter of multiple single-ground claims. ${ }^{58}$ The particular move of the Falkiner Court in treating comparison as operating on each ground individually disintegrates the claimants' group identities and degenerates the claim into multiple discrimination, rather than intersectional discrimination.

This is paradoxical given the Court's favourable final ruling and an otherwise generous framing of the flexible approach (which later became the official word of the Canadian Supreme Court in

\footnotetext{
${ }^{54}$ Ibid, para [77].

${ }^{55} \mathrm{Ibid}$.

${ }^{56}$ Ibid.

${ }^{57}$ Majury, above n 13, at 334.

${ }^{58}$ Gilbert and Majury, above n 13, at 134, 137.
} 
Withler - a single-ground claim that applied the flexible approach just as Falkiner). In principle, the flexible approach relaxes the requirement for finding mirror comparators. This liberating suggestion remains doctrinally unexploited and hence unverified in the dogmatic insistence of the Falkiner Court on comparators and in any other case since. ${ }^{59}$ But since comparison did win the day for the claimants in Falkiner (even if the comparators were framed for each ground separately), the flexible approach may have been too hasty in its suggestion to banish comparison from the discrimination inquiry completely. What becomes clear though is that the search for an instance of using comparison: (i) in an orderly fashion; and (ii) to identify similar and different patterns of group disadvantage based on multiple intersecting grounds, does not then terminate at flexible comparison.

\section{Contextual comparison}

The South African Constitutional Court has never considered comparators as essential in establishing discrimination. It has nevertheless resorted to contextual comparison in finding for unfair discrimination under section 9(3) of the Constitution, especially in the context of proving intersectional discrimination in Hassam. ${ }^{60}$ The case involved a constitutional challenge to the validity of statutory provisions which excluded widows of Muslim polygynous marriages from intestate succession. The South African Constitutional Court found that the impugned provisions constituted unfair discrimination under section 9(3) of the Constitution on the basis of gender, marital status and religion. Contextual comparison lay at the heart of this determination.

The Court used a range of comparators to identify multiple grounds of discrimination and then used comparative evidence in relation to these to establish similar and differences patterns of group disadvantage leading to unfair discrimination. In the first instance, the Court made seven sets of comparisons between widows in Muslim polygynous marriage and: widows married in terms of Marriage Act; widows in monogamous Muslim marriages; widows in polygynous customary marriages; ${ }^{61}$ women/widows; ${ }^{62}$ Muslims; ${ }^{63}$ Muslim men; ${ }^{64}$ and persons in other kinds of relationships. ${ }^{65}$ The differences between these groups and the claimant was then found to be:

on the grounds of, religion, in the sense that the particular religion concerned was in the past not one deemed to be worthy of respect; marital status, because polygynous Muslim marriages are not afforded the protection other marriages receive; and gender, in the sense that it is only the wives in polygynous Muslim marriage that are affect[ed] by the [exclusion]. ${ }^{66}$

\footnotetext{
${ }^{59}$ In fact, the Supreme Court did not capitalise on the rare opportunity of examining a possible intersectional claim (marital status and gender) in Quebec $v$ A, above $\mathrm{n} 45$, in reference to the flexible approach laid down in Withler. Quebec $v A$ involved a challenge to the provisions of Civil Code of Quebec which excluded cohabiting partners from the scope of patrimonial provisions relating to marriage. The majority found that the exclusion was not discriminatory under $s$ 15(1) of the Canadian Charter on the ground of marital status. But the Court was split variously. A majority of five judges (lead by Abella J) initially found that there was discrimination while the minority of four judges (lead by LeBel J) found that there was no discrimination; but in the final analysis, one of the minority judges (McLachlin CJ) joined the minority to find that the discrimination was ultimately justified under s 1 of the Charter. At no point did the split Court refer to comparative analysis for reaching its conclusions. The complicated comparative analyses in failed intersectional claims like Nova Scotia (Attorney General) v Walsh [2002] 4 SCR 325 (SCC) may have deterred the Court in going down the route of flexible comparisons despite approving the message from Withler. Quebec v A, above n 45, paras 163-169.

${ }^{60}$ Harksen $v$ Lane NO 1998 (1) SA 300 (CC). See also Pillay, above n 2, paras [42]-[44] (Langa CJ), [164]-[165] (O'Regan J) as regards the use of comparison under the Promotion of Equality and Prevention of Unfair Discrimination Act 2000.

${ }^{61}$ Hassam, above n 14 , para 31.

${ }^{62}$ Ibid, para 10.

${ }^{63} \mathrm{Ibid}$, paras $12,25,26,33$.

${ }^{64} \mathrm{Ibid}$, paras 10, 31 .

${ }^{65}$ Ibid, para 11.

${ }^{66} \mathrm{Ibid}$, para 34.
} 
In the second instance, discrimination based on these multiple grounds was found to be unfair under section 9(3) and unjustifiable under section 36 of the Constitution because it lead to redistributive and recognition harms such that the claimant group suffered not just 'significant and material disadvantage' but also from 'serious effects of non-recognition'. ${ }^{67}$ This conclusion was relative, ie established in relation to the position of the comparators groups.

In fact, the entire discrimination inquiry was pursued 'contextually and in the light of [the South African] history'. ${ }^{68}$ So what stands out in the Court's succinct but pointed reasoning is its contextual approach to establishing intersectional discrimination. The selection of comparators does not appear to be based on either strict or flexible comparison. The Court neither replaces each of the three personal characteristics of the claimant with the cognate privileged groups or replace all of them at the same time to find a single comparator group, nor does it facially abandon reference to comparators but end up using them in fact. The selection in Hassam is comprehensive, covering every group which could have been relevant in identifying multiple grounds and the disadvantage accruing on their basis. The choice and application of comparators in Hassam can be rationalised as a Venn diagram (Figure 1). The claimant, a widow in a Muslim polygynous marriage, lies at the intersection of three groups: Muslims (M), widows (W) and those in polygynous marriages $(\mathrm{P})$. Imagined thus, comparators in intersectional claims can pan the entire expanse of the Venn diagram such that any of the groups which share one, some or none of the claimant's personal characteristics are relevant in establishing similar and different patterns of group disadvantage based on marital status, gender, and religion.

There could be seven possible comparator groups as depicted in Figure $1^{69}$ - a group which does not share any of the claimant's personal characteristics and hence lies outside of the Venn diagram and constitutes part of the universal group of (i) others who are not Muslim, not widows and not in polygynous marriages; groups which do not share two of the claimant's personal characteristics: (ii) non-Muslim widows not in polygynous marriages (who do not share the claimant's religion and marital status), (iii) non-Muslims in polygynous marriages (who do not share the claimant's religion and gender), (iv) Muslims not in polygynous marriages (who do not share the claimant's marital status and gender); and finally groups which do not share one of the claimant's personal characteristics: (v) non-Muslim widows in polygynous marriages (who do not share the claimant's religion); (vi) Muslim widowers in polygynous marriages (who do not share the claimant's gender) and lastly, (vii) Muslim widows in monogamous marriages (who do not share the claimant's marital status).

The Court referred to the comparator groups in these ways. It accepted the comparators offered by the claimant which compared her position to (ii), (v) and (vii), ie all other groups of widows who were either not in polygynous marriages or were non-Muslim or both. These groups, in the context of the South African law governing marriages and customary unions, comprised of: widows married in terms of the Marriage Act (coinciding with (ii)), widows in monogamous Muslim marriages (coinciding with (vii)) and widows in polygynous customary marriages (coinciding with (v)). ${ }^{70}$ With this the Court delineated the specific disadvantage suffered by women on the basis of marital status, gender and religion considered together. At the same time, since all these groups had gender in common, they were used to assert the shared position of disadvantage of widows per se, since women 'constitute[d] a particularly vulnerable segment of the population'. ${ }^{71}$ Similarly, the comparator groups who were not widows but (iv) Muslims not in polygynous marriages and (vi) Muslims in polygynous marriages were used to establish patterns of discrimination based on religion since, as pointed out by the claimant and the Court both, these groups symbolised entrenched historical discrimination based on 'prejudice against the Muslim community. ${ }^{72}$ But they were also used to establish difference in this

\footnotetext{
${ }^{67}$ Ibid, paras $34,36,37,42$.

${ }^{68}$ Ibid, para 33.

${ }^{69}$ The exact number of possible comparators for different claims can be calculated based on the formula explained above (n 6)ff. As the succeeding discussion shows, they can also be identified with the help of a Venn diagram.

${ }^{70}$ Hassam, above n 14, paras 9, 31, 32.

${ }^{71}$ Ibid, para 10 .

${ }^{72} \mathrm{Ibid}$, paras 12, 25, 26, 33.
} 
(i) others

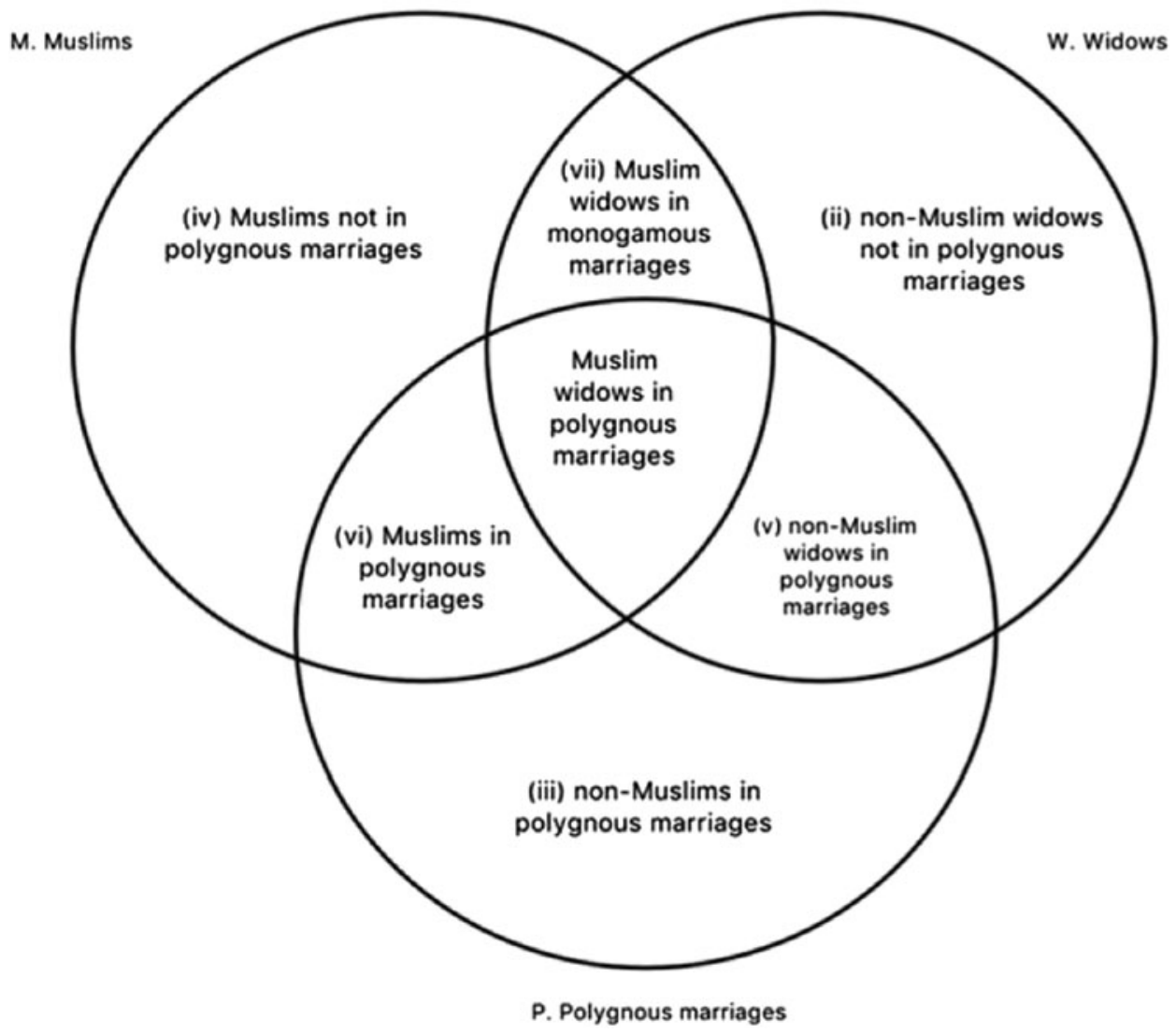

Figure 1. Comparators in Hassam (i)-(vii)

pattern of religious discrimination between Muslim men and Muslim women, because only the former could acquire multiple spouses. ${ }^{73}$ Finally, the claimant and the Court referred to (iii) non-Muslims in polygynous marriages, ie African customary marriages, to appreciate the specific disadvantage of Muslims in polygynous marriages, one which did not accrue on African customary marriages. ${ }^{74}$ Together these comparator groups helped establish both the specific nature of intersectional disadvantage suffered on the three grounds together, as well as the shared disadvantage between persons belonging to groups defined by one or two of the grounds. Note that the Court also moved beyond the binaries of Muslim/non-Muslim and polygynous/monogamous marriages to relate specifically to groups which made sense in the South African context, defined in terms of not just religion but those married under customary laws and under the Marriage Act, as well as those in other kinds of relationships. Comparison was thus not only made comprehensively but also contextually in light of the comparative evidence which fit the historical and current context of the claim.

In this way, the South African comparative approach differs from strict or flexible comparison. It is not strict like DeGraffenreid or Bahl, in that it does not focus on a single comparator or multiple single-ground comparators, but uses all comparators which could have been relevant in the context and useful in establishing the intersectional claim in reference to multiple grounds. It does not

\footnotetext{
${ }^{73}$ Ibid, paras 10, 31.

${ }^{74} \mathrm{Ibid}$, paras $11,34,46$.
} 
fragment or isolate the group identities of the claimant but considers them together, as a whole. The approach is not flexible like Falkiner, which excludes relevant comparators without explanation or relies on bogus comparisons or those too far removed to say anything pertinent about the claim. Where comparators were in fact not available, say the case of Muslim widowers in polygynous marriages - since Muslim women could not have multiple spouses - it did not use that fact to defeat the claim but in turn used it to establish patterns of sex discrimination. The chosen comparators were thus relevant, comprehensive, and most importantly useful in revealing similar and different patterns of group disadvantage, which is the crux of an intersectional claim.

Hassam's comparative approach can thus be distilled into two steps: first, drawing on all relevant permutations of comparators available for an intersectional claimant; secondly, examining the available evidence in relation to those comparators to draw conclusions about the nature of intersectional disadvantage suffered by the claimant. Both these steps individually feed into the two-stage discrimination inquiry traditionally followed by the South African Constitutional Court in establishing:(i) whether there was differentiation based on grounds; and (ii) if it was actually discriminatory, ie unfair. ${ }^{75}$ So at the first stage of the discrimination inquiry, one can delineate the grounds of differentiation with the help of comparators who do not share one, some or all of the personal characteristics of the claimant. At the second stage, one can establish the unfair impact on the claimant in reference to the relatively privileged position of the comparator groups from a range of contextual, historical, testimonial, anecdotal or statistical evidence. ${ }^{76}$ In this way, contextual comparison avoids both the 'arid and confusing disputes about the identification of the appropriate comparator ${ }^{\text {'77 }}$ in strict comparison or using flexible comparisons without further justification.

\section{Conclusion}

The US courts have limited intersectional discrimination to two grounds with its 'sex-plus' or 'raceplus' approach established through strict comparison. The UK government, despite enacting 'combination discrimination' for up to two grounds under section 14 of the Equality Act 2010, has not brought that provision into effect. While the Employment Tribunals have attempted to address dual ground claims outside of this statutory scheme, higher courts have not endorsed these efforts. ${ }^{78}$ The Canadian Supreme Court, on the other hand, has expressed its full support for potential intersectional claims, ${ }^{79}$ but has in fact never adjudicated on such a claim even when there were possibilities. ${ }^{80}$ The overall result, as Kotkin points out, is that 'the courts have basically given up on the complex subject' of evaluating multi-ground intersectional claims. ${ }^{81}$

The result though is unsurprising. As this article sought to show, the key tool of comparison in discrimination law has been central to the failures of test cases of intersectional discrimination. The doctrinal manifestations of strict and flexible comparative approaches in intersectional claims are rife with inconsistences. These are not merely operational in nature but go deep into the conceptual roots of the two approaches, telling us too little about how they are applied and can be useful in proving the distinct character of intersectional discrimination. Strict comparison, which is modelled on a

\footnotetext{
${ }^{75}$ The two-stage test for discrimination inquiry was devised by the South African Constitutional Court in Harksen $v$ Lane NO 1998 (1) SA 300 (CC) [54] (Goldstone J) and has been followed since.

${ }^{76}$ In fact, as Goldberg argues, contextual approach to comparison is primarily about 'what types of evidence will be considered': SB Goldberg 'Discrimination by comparison' (2011) 120 Yale Law Journal 728 at 810. See also B Baines 'Comparing women in Canada' (2012) 20 Feminist Legal Studies 89; M Jonker 'Comparators in multiple discrimination cases: a real problem or just a theory?' in M van den Brink, S Burri and J Goldschmidt (eds) Equality and Human Rights: Nothing But Trouble? (Utrecht University, 2015) p 211.

${ }^{77}$ Shamoon, above n 20, at [11] (Lord Nicholls) (emphasis supplied).

${ }^{78}$ Fiona O'Reilly v BBC [1982] 3 All ER 1124; Ministry of Defence $v$ DeBique [2010] IRLR 471.

${ }^{79}$ Withler, above $\mathrm{n} 2$, at [58], [63].

${ }^{80}$ See for example Egan v Canada [1995] 2 SCR 513 (SCC); Gosselin v Quebec (Attorney General) [2002] 4 SCR 429 (SCC); Mossop, above n 11; Quebec v A, above n 45.

${ }^{81}$ MJ Kotkin 'Diversity and discrimination: a look at complex bias' (2009) 50 William and Mary Law Review 1439 at 1462.
} 
single-ground vision of discrimination and insists on finding mirror comparator(s), is too unwieldy in pointing to a relevant comparator on a justifiable basis. Per Bahl and DeGraffenreid, the chosen comparator(s) is then applied in a way which tells us little about intersectionality as in similar and different patterns of group disadvantage. On the other hand, the flexible approach allows for comparison to be with a mirror comparator, a number of different comparators, or no comparator at all. While this formulation appears promising, its application by the Falkiner Court shows a preference for multiple strict or mirror comparisons based on each ground, highlighting an understanding similar to singleground or multiple discrimination rather than intersectional discrimination. It also lacks a background principle which guides the flexibility in choosing comparators, reinstating the concerns identified in using strict comparison. Thus, the landmark intersectional claims in DeGraffenreid, Bahl, and Falkiner do not just represent the initial impediments in translating intersectionality into discrimination law but mark the continuing struggle in making it mainstream. In contrast, the contextual approach, as exemplified in Hassam, engages with all relevant comparators in an intersectional claim, ie the entire breadth of comparator groups which do not share one, some or all of the personal characteristics of the claimant. These comparators are then viewed in context and in light of the probative evidence at hand to appreciate similar and different patterns of group disadvantage. This approach is normatively aligned with intersectional discrimination in that the exercise helps identify such patterns as based on multiple grounds.

A broad contextual approach like South Africa's is inevitably based on its own legal context. The right to equality and non-discrimination not only has a constitutional status - it is considered foundational to the broader transformative aims of the Constitution. ${ }^{82}$ The South African model thus goes above and beyond the equal treatment or equal opportunity model of discrimination law and aspires to the equality of results. This background appears similar to the radical potential of the Canadian Charter, which is interpreted as guaranteeing substantive equality under section $15{ }^{83}$ The South African approach may map directly onto the Canadian substantive equality framework which, too, prefers contextual analysis of discrimination. ${ }^{84}$ Extending its contextual analysis from single-ground to intersectional discrimination may prove to be easier and more normatively justifiable than using flexible comparisons. But both section 9 of the South African Constitution and section 15 of the Canadian Charter are different from the legislative frameworks which are far more limited, such as employment discrimination in the US under Title VII and Great Britain under the Equality Act 2010. Questions of discrimination are asked in narrower contexts and applied far more pointedly to the situations at hand than in cases of constitutional adjudication which pan beyond the responsibility of a single employer to the standards applicable to the whole State. Yet, the nature of discrimination inquiry itself opens up all adjudicators to broader questions of context in which that discrimination operates - of sexism, racism, ageism, ableism, homophobia, etc. Thus, in a long line of single-ground discrimination cases, the UK courts have consistently found that the 'relevant circumstances' or 'context' for comparison in employment cases includes 'all the circumstances which are relevant to the way in which the [claimant] has been treated' ${ }^{85}$ Individual cases of discrimination beyond employment, concerning denial of services or benefits etc, have also relied on broader patterns of group disadvantage and contextual comparisons in gauging whether the discriminatory treatment or effects were

\footnotetext{
${ }^{82}$ See especially section 1 of the South African Constitution which lays out the foundational values of South Africa as based on human dignity, the achievement of equality, the advancement of human rights and freedoms, non-racialism and nonsexism: C Albertyn and B Goldblatt 'Facing the challenge of transformation: difficulties in the development of an indigenous jurisprudence of equality' (1998) 14 South African Journal on Human Rights 248.

${ }^{83}$ Andrews, above n 21, at 164-171; $R$ v Kapp [2008] 2 SCR 483 (SCC) at [14]-[18].

${ }^{84}$ Withler, above n 2, at para [43] ('The central and sustained thrust of the Court's s 15(1) jurisprudence has been the need for a substantive contextual approach and a corresponding repudiation of a formalistic "treat likes alike" approach').

${ }^{85}$ Shamoon, above n 20, at [48] (Lord Hope), [131] (Lord Rodger) ('the comparison should proceed on the basis of all the circumstances that are relevant to the way that the employer treated the female employee who complains of discrimination'). See also Chief Constable of the West Yorkshire Police v Khan [2001] 1 WLR 1947, HL and Nagarajan v London Regional Transport [1998] IRLR 73.
} 
based on a personal characteristic. ${ }^{86}$ The question that remains is whether evidence relating to such broader patterns of group disadvantage which fall within the 'relevant circumstances' or the 'context' of a case can be relied upon to establish claims of intersectional discrimination based on multiple grounds and multiple comparisons? Goldberg answers this question in the affirmative in the context of the US discrimination law. ${ }^{87}$ The UK courts too may find inspiration in what may at first blush appear to be a free flowing form of comparison but is in fact, per Hassam, far more precise and relevant in establishing intersectional claims.

Ultimately, the immediate intuitive grasp of comparison is what makes it so appealing in discrimination law. Its application can reveal both the disadvantage suffered and its basis in grounds. Even if strict and flexible approaches have failed to do exactly this, contextual comparison does help establish intersectional disadvantage suffered on the basis of multiple grounds. With the example of Hassam, this article has outlined the conceptual and doctrinal application of contextual comparison to fulfil this aim. The hope is that it revives the interest in claiming intersectional discrimination on multiple grounds - in understanding how it is to be done, in actually doing so by bringing and arguing such cases, and in adjudicating them successfully.

\footnotetext{
${ }^{86}$ Preddy v Bull [2013] UKSC 73 at [52]-[53] (Baroness Hale); Walker $v$ Innospec Limited [2017] UKSC 27 at [5], [17]-[19] (Lord Kerr).

${ }^{87}$ Goldberg, above n 76.
}

Cite this article: Atrey S (2018). Comparison in intersectional discrimination. Legal Studies 38, 379-395. https://doi.org/ $10.1017 / 1$ st.2017.17 